\title{
Measuring Parent Perceptions of School Climate
}

\section{Citation}

Schueler, Beth E., Lauren Capotosto, Sofía Bahena, Joseph McIntyre and Hunter Gehlbach. 2014. Measuring Parent Perceptions of School Climate. Psychological Assessment xx, no. x:xx-xx.

\section{Permanent link}

http://nrs.harvard.edu/urn-3:HUL.InstRepos:11143738

\section{Terms of Use}

This article was downloaded from Harvard University's DASH repository, and is made available under the terms and conditions applicable to Open Access Policy Articles, as set forth at http:// nrs.harvard.edu/urn-3:HUL.InstRepos:dash.current.terms-of-use\#OAP

\section{Share Your Story}

The Harvard community has made this article openly available.

Please share how this access benefits you. Submit a story.

Accessibility 


\section{Measuring Parent Perceptions of School Climate}

Beth E. Schueler, Lauren Capotosto, Sofía Bahena, Joseph McIntyre and Hunter Gehlbach Harvard University

Author Note

Beth E. Schueler, Lauren Capotosto, Sofía Bahena, Joseph McIntyre and Hunter Gehlbach, Harvard Graduate School of Education, Harvard University.

This research was supported by generous funding from SurveyMonkey. The authors would like to thank all of the participating schools, parents, and expert scale reviewers, as well as Karen Mapp, Richard Weissbourd and the members of the fall 2012 Doctoral Research Practicum on “Using Quantitative Methods to Make Causal Inferences about the Consequences of Educational Initiatives and Policies” for their contributions to this article. The authors take full responsibility for any shortcomings.

Portions of the findings from this article were presented at the 2013 American Education Research Association Conference in San Francisco, California.

This article may not exactly replicate the final version published in the APA journal. It is not the copy of record. http://www.apa.org/pubs/journals/pas/index.aspx

Correspondence concerning this article should be addressed to Beth E. Schueler, Harvard Graduate School of Education, Longfellow Hall 328, 13 Appian Way, Cambridge, MA 02138. Email: beth_schueler@mail.harvard.edu or Hunter Gehlbach: hunter_gehlbach@gse.harvard.edu 
Running head: MEASURING PARENT PERCEPTIONS OF SCHOOL CLIMATE

\begin{abstract}
Parents' attitudes about their children’s schools matter. Their views can shape their children’s attitudes about school, affect their levels of family-school engagement, and influence their residential and school enrollment decisions. This paper describes the development of a survey scale to assess parent perceptions of the climate of their child's school. Our comprehensive scale development process incorporated feedback from academics and potential respondents from the outset of the design process to enhance scale quality. We conducted three studies with national samples of parents $(n=385 ; n=253 ; n=266)$ to gather evidence of scale score reliability and valid score inferences based on convergent/discriminant validity. Through confirmatory factor analysis we identified a theoretically grounded factor structure that fit the data well.

Interestingly, we found no evidence that parental response patterns distinguish between academic and social elements of school climate. Furthermore, we found that parents of younger children, on average, had a more positive perception of the school's climate than parents of older children. We conclude by discussing how researchers and Pre-K - 12 schools and districts can use the scale to aid school improvement efforts.
\end{abstract}

Keywords: school climate, scale development, survey/questionnaire design, parent involvement, family engagement, family-school relationships 
Running head: MEASURING PARENT PERCEPTIONS OF SCHOOL CLIMATE

\section{Measuring Parent Perceptions of School Climate}

Parents, ${ }^{1}$ attitudes about their children's schools can have far-reaching effects. Their perceptions may influence student attitudes about school, whether and how parents engage with the school, and even parents' decisions about which school their child will attend. As interest in family-school engagement and school choice increases (Mapp, 2012), schools’ need to accurately and efficiently measure parent attitudes also grows. In this paper, we 1) describe the process we used to develop a robust measure of parent perceptions of school climate, 2) use data from three national samples of parents to identify a factor structure that fits the data well, and 3) provide evidence of score reliability and validity of inferences for particular uses of the scale. We conclude by describing how practitioners and researchers might use the tool.

\section{Background: Why Measure Parent Perceptions of School Climate?}

Jonathan Cohen, of the National School Climate Center, and his colleagues (2009) described school climate as, "the quality and character of school life [which is] based on patterns of people’s experiences of school life and reflects norms, goals, values, interpersonal relationships, teaching and learning practices, and organizational structures” (p. 182). Students’ and teachers' perceptions of climate are associated with a host of important student outcomes, including attendance (Rumberger, 1987), discipline problems (Wu, Pink, Crain, \& Moles, 1982), mental health (Payton et al., 2008), drug use (LaRusso, Romer, \& Selman, 2008), and academic achievement (Stewart, 2008). Climate is also associated with teacher job satisfaction (Grayson \& Alvarez, 2008), attrition (Miller, Brownell, \& Smith, 1999), and school-level improvement efforts (Bryk, Sebring, Allensworth, Luppescu, \& Easton, 2010).

\footnotetext{
${ }^{1}$ We use "parent” as a shorthand to describe all types of primary caregivers including legal guardians, grandparents, aunts, etc.
} 
Running head: MEASURING PARENT PERCEPTIONS OF SCHOOL CLIMATE

Although many climate measures focus on student and teacher perceptions, some scholars have argued that measurement tools must also gauge parent perspectives to get an accurate picture of climate (Nassar-McMillan, Karvonen, Perez, \& Abrams, 2009). Furthermore, there are good reasons to measure parent perceptions on their own. Although parent perceptions may not directly influence student outcomes, they may affect them through three indirect pathways.

First, parents' perceptions of their child’s school may influence their child’s perceptions of that school (Cohen, McCabe, Michelli, \& Pickeral, 2009). We know that parental attitudes can influence children's attitudes regarding school (Eccles, 2006; Harackiewicz, 2012) and that student attitudes about their school are closely tied to their motivation, behavior, and academic performance (Roeser \& Eccles, 1998). Thus, parent perceptions may influence children’s perceptions of the school climate, ultimately affecting student achievement outcomes.

Second, parents’ impressions of school climate can influence whether and how families engage with the school (Hoover-Dempsey et. al, 2005). As Griffith’s (1998) analyses illustrate, positive perceptions of school climate among parents are associated with higher levels of parent involvement. Given that family engagement with children’s learning is strongly associated with students’ academic outcomes and well-being (Hill \& Tyson, 2009; Jeynes, 2005), schools might better support student success by understanding and improving the way parents view the school.

Finally, many parents decide where to live and send their children to school, in part, based on their perceptions of school climate. Twenty-seven percent of parents who took the 2007 National Household Education Survey reported that they moved to their current neighborhood for the school (Grady, Bielick, \& Aud, 2010). Conversely, negative perceptions of climate are associated with parents’ decisions to withdraw students from schools (Bukhari \& Randall, 2009). 
Running head: MEASURING PARENT PERCEPTIONS OF SCHOOL CLIMATE

Given the increasing prevalence of school choice (e.g., charter schools), school leaders must understand and be able to assess parents' views of school climate to attract and retain students. Existing Instruments: Why Develop a New Tool?

Tools designed for students and educators may be inappropriate for use with parent populations given that few parents are regularly present in schools. Thus, adapting one of the many student (e.g., Zullig, Koopman, Patton, \& Ubbes, 2010) or teacher (e.g., Rhodes, Camic, Milburn, \& Lowe, 2009) measures may be ineffective. Furthermore, existing tools that are designed for parents are often lengthy (e.g., Guo, Choe, \& Higgins-D’Alessandro, 2011) or focus on a particular facet of climate such as safety (e.g., NCES, 1996). Finally, some existing measures do not take advantage of best practices in survey design. In contrast, our scale was explicitly designed to assess parent perceptions, relies on best practices in survey design, and is parsimonious while still assessing a broad conception of school climate.

\section{Scale Development Process}

We developed our scale using Gehlbach and Brinkworth’s (2011) six-step process for designing survey instruments. The goal of this process is to focus on validity from the outset by front-loading feedback from both scholars and potential respondents. Our first step was to review the relevant literature to identify key aspects of climate and possible indicators. We found that researchers have generally conceived of school climate as having four dimensions: (1) teaching and learning, (2) relationships, (3) safety, and (4) physical environment (Cohen et al., 2009). However, scholars diverge about which aspects are most important to measure (Cohen \& Geier, 2010). Therefore, in Step 2, we included prompts on each of the four domains in the interview protocol we used to learn how parents conceptualized school climate. Specifically, we conducted 45 to 60 minute open-ended interviews and focus groups with nine parents who were diverse in 
Running head: MEASURING PARENT PERCEPTIONS OF SCHOOL CLIMATE

terms of their native language, child's age, and the type of school their child attended (e.g., public/private; urban/suburban). Interestingly, our respondents emphasized the teaching/learning and social dimensions of climate frequently, but rarely mentioned safety and physical climate. When prompted, parents did not view the physical climate as a primary indicator. In contrast, parents cared about safety, but conflated it with social climate. Therefore, we decided to develop two sub-scales to measure academic and social climate, defining academic climate as: parent perceptions of how supportive the school environment is for student learning, and social climate as: how supportive the environment is for student well-being and social development.

Our third step was to compare our list of literature-based indicators with interview-based indicators to identify those that appeared in both and to note differences in the terminology used by academics and parents. Fourth, we developed items that assessed key indicators of climate. We particularly emphasized those indicators that we found in both the literature and parent interviews and worded items in accordance with parents’ language. For example, what researchers called "student engagement” parents described as “classes that motivate students to learn.” We also relied on research-based best practices for survey development. We wrote items as questions rather than statements, used construct specific response anchors instead of numbers or agree-disagree response anchors, and avoided double-barreled and negatively worded items (Artino, Gehlbach \& Durning, 2011). We initially developed 33 items, some of which covered overlapping domains, based on the assumption that we would later eliminate those that did not perform well during the last two steps of the development process or in pilot-testing.

Fifth, we subjected our items to an expert review procedure. Twenty scholars and practitioners familiar with school climate completed an online survey to provide feedback on the clarity and relevance of items, possible missing items, and appropriateness for parents of all 
Running head: MEASURING PARENT PERCEPTIONS OF SCHOOL CLIMATE

cultural and linguistic backgrounds, and with children of all ages. Sixth, we employed a cognitive pretesting procedure with 10 parents to ensure potential respondents understood the items as we intended (Karabenick et al., 2007). We conducted 40 to 60 minute one-on-one interviews in which we first asked parents to restate each question in their own words, without using words from the item itself, and then to "think aloud" as they came to their own answer to the question. These last two steps helped us improve the quality of our items in several ways. For instance, although experts felt the item, “How well do administrators at your child's school create a school culture that helps students learn?” was highly relevant, cognitive pretesting revealed that the word “culture” caused confusion for parents. For instance, one respondent described a cultural program at her child's school when talking through her answer. As a result, we changed the word "culture" to "environment" to improve the likelihood that we capture parents’ overall impressions of the academic climate.

\section{Methodology for the Three Studies}

Each sample was drawn from SurveyMonkey's national panel $(n=385 ; n=253 ; n=266){ }^{2}$ Participants were parents of one or more children between the ages of 5 and $18 .^{3}$ These samples were slightly more affluent and educated than the U.S. as a whole (see the online supplemental materials for detailed descriptions of each sample). For Study One, our climate scale included 22 items. Results from this study led us to shorten the scale to seven items for Studies Two and Three (see Table 1). In Study Three, we gathered evidence of convergent and discriminant validity of inferences by administering four pre-existing scales: "Satisfaction with School," “Endorsement of Child's School,” "Efficacy for Helping the Child Succeed in School” and “Time and Energy" in addition to our climate measure. These measures are described in the

2 Details on the panel provided at: http://help.SurveyMonkey.com/app/answers/detail/a_id/5654

${ }^{3}$ We asked respondents with multiple children to focus on one child throughout the survey. 
Running head: MEASURING PARENT PERCEPTIONS OF SCHOOL CLIMATE

supplemental materials. Our primary data analytic procedures revolved around using confirmatory factor analysis (CFA) to provide evidence of the factor structure of the scale, ${ }^{4}$ as well as reliability analyses and descriptive statistics to assess item- and scale-level variability.

\section{Studies One and Two: Identifying and Replicating the Factor Structure}

The primary goal of Study One was to identify a well-fitting, theoretically grounded factor structure for our instrument. Based on Cohen, Pickeral, and McCloskey’s (2009) conception of school climate and our interviews with parents, we hypothesized that separate academic and social climate factors would emerge. However, we also tested the fit of a single factor model given that other scholars have measured climate as a single construct when surveying parents (Hamilton et al., 2010).

We first examined the fit of the 22-item two-factor model with the social factor loading on 13 items and the academic factor on nine items, allowing the two factors to covary. Although the fit was adequate, ${ }^{5}$ we found that the latent academic and social climate factors were essentially indistinguishable $(r=1.00, p<.001) .{ }^{6}$ Our comparison between the two-factor and single-factor model revealed that there was no statistically significant difference in fit $\left(\chi^{2}\right.$ difference $=2.20 ; d f=1 ; p=.14)$. For the single factor model, although we reject the null hypothesis that there is no difference between our single-factor model and a model that exactly replicates the data $\left(\chi^{2}=469.55, d f=209, p<.001\right)$, we conclude the fit is acceptable in light of other indicators $(C F I=.98, R M S E A=.06,90 \% C I[.05, .07])$. Only two of the correlation residuals (1\%) were higher than .10 (the largest had an absolute value of .11) and none of the modification

4 We conducted all analyses using Mplus version 7. We used the categorical option, robust weighted least squares with adjusted mean and variance (WLSMV) estimation, and the diff test function when comparing nested models (Asparouhov \& Muthén, 2006).

5 We provide a full set of fit statistics in the supplemental online materials.

6 The correlation was actually .996 (rounded to 1.00). We observed no warnings or error messages and replicated this finding in Studies Two and Three. 
Running head: MEASURING PARENT PERCEPTIONS OF SCHOOL CLIMATE

indices were greater than 10 (Kline, 2011). Thus, we adopted the single-factor approach going forward based on the assumption that users would find it more straightforward.

Once we adopted the single-factor approach, we realized that the resultant 22-item scale was much longer than necessary to obtain reliable scores. Informed by our literature review and focus groups, we carefully selected items for a more succinct scale based on how well an item covered key aspects of climate and how likely it was to measure the same variability as other items. For example, parents are unlikely to report that teachers are committed to helping children learn if teachers have little respect for students. Indeed, the correlation between our two teacherrelated items was high $(r=.70 ; p<.05)$. Thus, we retained "Overall, how much respect do you think the teachers at your child's school have for the children?" and discarded, "How committed are teachers at your child's school to helping children learn?”

For the seven-item single factor model, we failed to reject the null hypothesis that there is no significant difference between our model and a model that exactly replicates the data $\left(\chi^{2}=\right.$ 15.93, $d f=14, p=.32)$ and fit indices were well within acceptable ranges $(C F I=.99 ; R M S E A=$ $.02,90 \% C I[.00, .06])$. The absolute value of the largest correlation residual was .03 and the largest modification index was 2.04. We report the standardized factor loadings (.88 to .64) in Figure 1 . The relatively high loadings demonstrate that the items function as strong indicators of parent perceptions of climate, and total scores had strong internal consistency ( $\alpha=.89$ ).

To ensure that we were not losing substantial information by shortening the scale, we generated factor scores from both the 22-item single-factor and seven-item single-factor model. The correlation between these scores was very high $(r=.96, p<.001)$, suggesting we were coming to nearly identical conclusions using the seven-item scale and the longer version. For the sake of parsimony and practical concern for scale users, we prefer the seven-item approach. 
Running head: MEASURING PARENT PERCEPTIONS OF SCHOOL CLIMATE

We replicated the factor structure of the seven-item single-factor model with the Study

Two sample $\left(\chi^{2}=25.12 ; d f=14, p=.03 ; C F I=.99 ; R M S E A=.04,90 \% C I[.01, .07]\right)$. The largest correlation residual had an absolute value of .04 and all modification indices were smaller than one. The factor loadings were moderate to high (see Figure 1) and total scores had strong internal consistency ( $\alpha=.91$ ). The fit of the two factor solution was again no better than the single-factor model $\left(\chi^{2}\right.$ difference $\left.=1.33 ; d f=1 ; p=.25\right)$ and the social and academic factors were highly correlated $(r=.99 ; \mathrm{p}<.001)$, providing further support for the single-factor approach.

\section{Study Three: Convergent/Discriminant Validity}

In Study Three we replicated our results with a third sample. The single-factor model had adequate fit $\left(\chi^{2}=27.93, d f=14, p=.02 ; C F I=1.00 ; R M S E A=.07,90 \% C I[.03\right.$ to .10$\left.]\right)$. The highest correlation residual had an absolute value of .10 and none of the modification indices were larger than seven, indicating that the magnitude of misfit was not troublesome.

Furthermore, the one-factor model did not have significantly worse fit than the two-factor model $\left(\chi^{2}\right.$ difference $\left.=.95 ; d f=1 ; p=.33\right)$. The total scores have strong internal consistency $(\alpha=.91)$.

The bivariate correlations between our scale and four additional scales we administered to Study Three participants provide evidence of convergent and discriminant validity of inferences. We hypothesized that our scale would correlate strongly with other scales aimed at assessing parental perceptions of school environments, but no more than moderately with scales assessing distinct constructs such as parents' self-efficacy and life contexts. Indeed, we found that our climate scale had a high, positive correlation with the NCES "Satisfaction with School” scale ( $r$ $=.81 ; p<.05)$ and the Fast Track "Parent's Endorsement of Child's School" scale $(r=.84 ; p<$ .05), but was not as highly correlated with Hoover Dempsey et al.’s Parent Self-Efficacy scale ( $r$ $=.20 ; p<.05)$ and Walker et al.'s “Time and Energy for Involvement” scale $(r=.38 ; p<.05)$. 
Running head: MEASURING PARENT PERCEPTIONS OF SCHOOL CLIMATE

These findings were consistent with the notion that parents may make more time to engage with the school if the climate is positive, but that these scales still measure different constructs.

\section{Final Analyses with the Full Sample}

Since all respondents came from the same underlying sample of panelists, we pooled the three samples from our studies $(n=904)$ to examine whether our items capture adequate variability, and use the known-groups method to gather additional evidence of validity. We report the means (ranging from 3.38 to 4.05), standard deviations (ranging from .81 to 1.04) and interitem correlations for our items in Table 4 of the supplemental materials. Respondents utilized the full range of response options on each item. In combination with the moderately large standard deviations, these data indicate that our items capture ample variation between respondents.

Next, we relied on the known-groups method by identifying respondents in our sample with expected differences on our measure. In this case, we expected that parents of children in elementary grades (Pre-K-5 $5^{\text {th }}$ ) would have more positive perceptions of climate than secondary school parents $\left(6^{\text {th }}-12^{\text {th }}\right)^{7}$ given previous research showing children tend to perceive a substantial drop in the positivity of the school climate as they leave elementary school (Eccles et al., 1993).

We first examined whether our measure was invariant across school levels (elementary vs. secondary) through a MIMIC approach (Kline, 2011). We combined our measurement model with a direct path from a binary "School level” indicator to the latent climate variable. Although the chi-square test of model fit leads us to reject the null hypothesis that there is no difference between our model and the saturated model $\left(\chi^{2}=74.82 ; d f=20 ; p<.001\right)$, the other fit statistics were acceptable $(C F I=.99 ; R M S E A=.06,90 \%$ CI $[.05, .07])$. The highest correlation residual had a value of .04, and the factor loadings did not shift dramatically when we added the "School

7 We specify elementary and secondary "grades" as opposed to "schools" because we have data on the children's grades, but not the grade configurations of the schools they attend. 
Running head: MEASURING PARENT PERCEPTIONS OF SCHOOL CLIMATE

level” predictor. However, there were four modification indices above Kline’s suggested cutoff of 10 (the largest was 17.01). To examine the degree to which this model misfit would affect our results, we compared the factor scores generated by a constrained model and a model allowed to vary for elementary vs. secondary parents. These scores were highly correlated $(r=.94 ; p<$ .001) suggesting that although the unconstrained model had statistically significantly better fit, practically, both models pointed us toward nearly identical conclusions about perceptions of climate. This gave us confidence in our ability to compare parent perceptions across grade levels.

Our substantive findings are consistent with our hypothesis that parents of younger students would have more positive perceptions of climate than parents of older students. On average in our sample, elementary parents give a half of a standard deviation higher ratings to their child's school climate than parents of $6-12^{\text {th }}$ grade students $(\beta=-.57 ; S E=.09 p<.001)$. This result provides further confidence that our scale appears to be functioning as intended.

\section{General Discussion and Conclusions}

The findings from this series of studies suggest that educators and scholars should have reasonable confidence in using this scale to measure parent perceptions of school climate. In addition to focusing on parents (rather than students or teachers), this scale: efficiently covers a broad conception of academic and social climate, adheres to best practices in survey design, and incorporates feedback from potential respondents and experts in the field of school climate and family-school relationships. We established that a single factor had reasonable fit and demonstrated high score reliabilities across three national samples, gathered evidence of convergent and discriminant validity of scores, and provided further evidence of the validity of inferences drawn based on our scale through a known-groups approach. 
Running head: MEASURING PARENT PERCEPTIONS OF SCHOOL CLIMATE

We speculate that the scale may help school leaders and researchers explore important future research questions. For instance, schools might use the scale to examine whether different groups of families diverge in their perceptions of the climate or whether families' perceptions change over time. Districts implementing school improvement initiatives might use the scale to determine whether parent attitudes improve as a result of the interventions. Researchers can use the scale to learn how parent perceptions of climate influence their school enrollment decisions.

Throughout the process of developing our climate scale we made a series of tradeoffs. Our tool has the advantage of being short and convenient to administer. Although the scale provides a high-level view of school climate, it may be inappropriate for researchers interested in a finegrained analysis of the sub-domains of school climate. For instance, because our scale does not explicitly cover safety and physical environment, researchers with a particular interest in these domains may consider concurrently administering additional scales with our scale.

Finally, our study is not without limitations. In particular, our samples were, on average, slightly wealthier, more highly educated, and less likely to speak a language other than English at home than the average American. Additionally, since our respondents opted to take our survey, they may be unique on other unobservable characteristics, such as motivation or interest in education. Future research should examine how the scale functions with different samples.

It is important to accurately measure families' perceptions of their children's school environments, given they can influence children's attitudes about school, the level and quality of family-school engagement, and families’ decisions about where to send their children to school. Our hope is that this new tool will contribute to advancing understanding regarding parents' views of school climate and ultimately help to improve learning environments for children. 
Running head: MEASURING PARENT PERCEPTIONS OF SCHOOL CLIMATE

\section{References}

Artino, A. R., Jr., Gehlbach, H., \& Durning, S. J. (2011). AM Last Page: Avoiding five common pitfalls of survey design. Academic Medicine: Journal Of The Association Of American Medical Colleges, 86(10), 1327-1327. doi: 10.1097/ACM.0b013e31822f77cc

Asparouhov, T., \& Muthén, B. O. (2006). Robust chi square difference testing with mean and variance adjusted test statistics (Mplus Web Notes No. 10). Retrieved from http://www.statmodel.com/download/webnotes/webnote10.pdf

Bryk, A. S., Sebring, P. B., Allensworth, E., Luppescu, S., \& Easton, J. Q. (2010). Organizing schools for improvement: Lessons from Chicago. Chicago: University of Chicago Press.

Bukhari, P. \& Randall, E.V. (2009): Exit and entry: Why parents in Utah left public schools and chose private schools. Journal of School Choice: Research, Theory, and Reform, 3(3), 242-270. doi:10.1080/15582150903304746

Cohen, J. \& Geier, V.K. (2010). School climate research summary: January 2010. School Climate Brief, 1(1). Retrieved from http://www.schoolclimate.org/climate/documents/SCBrief_ v1n1_Jan2010.pdf

Cohen, J., McCabe, E., Michelli, N. \& Pickeral, T. (2009). School climate: Research, policy, practice, and teacher education. Teachers College Record, 111(1), 180-213.

Cohen, J., Pickeral, T. \& McCloskey, M. (2009). The challenge of assessing school climate. Educational Leadership, 66(4). Retrieved from http://www.ascd.org/publications/educational-leadership/dec08/vol66/num04/TheChallenge-of-Assessing-School-Climate.aspx

Eccles, J. (2006). Families, schools, and developing achievement-related motivations and engagement. In J. Grusec, and P. Hastings (Ed.), Handbook of Socialization: Theory and 
Running head: MEASURING PARENT PERCEPTIONS OF SCHOOL CLIMATE

Research (pp. 665 - 691), New York, NY: Guilford Press.

Eccles, J. S., Midgley, C., Wigfield, A., Buchanan, C. M., Reuman, D., Flanagan, C., \& Mac Iver, D. J. (1993). Development during adolescence: The impact of stage-environment fit on young adolescents' experiences in schools and in families. Special Issue: Adolescence. American Psychologist, 48(2), 90-101. doi: 10.1037/0003-066X.48.2.90

Gehlbach, H., \& Brinkworth, M. E. (2011). Measure twice, cut down error: A process for enhancing the validity of survey scales. Review of General Psychology, 15(4), 380-387. doi: $10.1037 / \mathrm{a} 0025704$

Grady, S. Bielick, S. \& Aud, S. (2010). Trends in the use of public school choice: 1993 to 2007 (NCES 2010-004). National Center for Education Statistics, Institute of Educational Sciences, U.S. Department of Education. Washington, DC.

Grayson, J. \& Alvarez, H. (2008). School climate factors relating to teacher burnout: A mediator model. Teaching and Teacher Education, 24, 1349-1363. doi: 10.1016/j.tate.2007.06.005

Griffith, J. (1998). The relation of school structure and social environment to parent involvement in elementary schools. The Elementary School Journal, 99(1), 53-80.

Guo, P., Choe, J.\& Higgins-D’Alessandro, A. (2011). Report of construct validity and internal consistency findings for the comprehensive school climate inventory. Retrieved from http://www.schoolclimate.org/climate/documents/Fordham_Univ_CSCI_development_re view_2011.pdfhttp://nces.ed.gov/pubs2009/2009047 1.pdf

Hill, N. E., \& Tyson, D. F. (2009). Parental involvement in middle school: A meta-analytic assessment of the strategies that promote achievement. Developmental Psychology, 45(3), 740-763. doi:10.1037/a0015362 
Running head: MEASURING PARENT PERCEPTIONS OF SCHOOL CLIMATE

Hoover-Dempsey, K. V., Walker, J. M. T., Sandler, H. M., Whetsel, D., Green, C. L., Wilkins, A. S., \& Closson, K. (2005). Why do parents become involved? Research findings and implications. The Elementary School Journal, 106(2), 105-130. doi: 10.1086/499194

Jeynes, W. H. (2005). A meta-analysis of the relation of parental involvement to urban elementary school student academic achievement. Urban Education, 40(3), 237-269. doi: $10.1177 / 0042085905274540$

Karabenick, S.A., Woolley, M.E., Friedel, J.M., Ammon, B.V., Blazveski, J., Bonney, C.R., De Groot, E., Gilbert, M.C., \& Musu, L. (2007). Cognitive processing of self-report items in educational research: Do they think what we mean? Educational Psychologist, 42(3), 139151. doi: $10.1080 / 00461520701416231$

Kline, R. B. (2011). Principles and practice of structural equation modeling (3rd ed.). New York: Guilford Press.

Mapp, K. (2012). Title I and parent involvement: Lessons from the past, recommendations for the future. American Enterprise Institute and Center for American Progress: Washington, D.C. Retrieved from http://www.aei.org/files/2012/03/06/-title-i-and-parentalinvolvement_091556561921.pdf

Miller, D. M., Brownell, M. T., \& Smith, S. W. (1999). Factors that predict teachers staying in, leaving, or transferring from the special education classroom. Exceptional Children, 65, 201-218.http://www.fasttrackproject.org/techrept/p/ptp/ptp2tech.pdf

Nassar-McMillan, C., Karvonen, M., Perez, T., and Abrams, L. (2009). Identity development and school climate: The role of the school counselor. Journal of Humanistic Counseling, Education, and Development, 48, 195-214. doi: 10.1002/j.2161-1939.2009.tb00078.x.

National Center for Educational Statistics (1996). 1993 National Household Education Survey 
Running head: MEASURING PARENT PERCEPTIONS OF SCHOOL CLIMATE

Questionnaires: Screener and on School Safety and Discipline. Retrieved from http://nces.ed.gov/nhes/pdf/ssd/93_ssd.pdf

National Center for Educational Statistics (2007). National Household Education Surveys

Program. Retrieved from http://nces.ed.gov/nhes/questionnaires.asp

NORC (1988). Parent questionnaire: National education longitudinal study of 1988. Retrieved from http://nces.ed.gov/surveys/nels88/pdf/09_BY_Parent.pdf

Rhodes, J., Camic, P., Milburn, M., and Lowe, S. (2009). Improving middle school climate through teacher-centered change. Journal of Community Psychology, 37(6), 711-724. doi: 10.1002/jcop.20326

Roeser, R.W., \& Eccles, J.S. (1998). Adolescents perceptions of middle school: Relation to longitudinal changes in academic and psychological adjustment. Journal of Research on Adolescence, 8(1), 123-158. doi: 10.1207/s15327795jra0801_6

Stewart, E. (2008). School structural characteristics, student effort, peer associations, and parental involvement: The influence of school- and individual-level factors on academic achievement. Education and Urban Society, 40(2), 179-204. doi:

10.1177/0013124507304167 http://quickfacts.census.gov/gfd/states/00000.html

Walker, J. M. T., Wilkins, A. S., Dallaire, J. R., Sandler, H. M., \& Hoover-Dempsey, K. V. (2005). Parental involvement: Model revision through scale development. The Elementary School Journal, 106(2), 85-104. doi: 10.1086/499193

Zullig, K.J., Koopman, T.M., Patton. J.M. \& Ubbes, V.A. (2010). School climate: Historical review, instrument development, and school assessment. Journal of Psychoeducational Assessment, 28(139), 139-152. doi: 10.1177/0734282909344205 
Table 1

Questions and Answer Choices for the Seven-item School Climate Scale

\begin{tabular}{|c|c|c|c|c|c|c|c|}
\hline Items & \multicolumn{7}{|c|}{ Answer Choices } \\
\hline \multicolumn{8}{|l|}{ Social Climate } \\
\hline $\begin{array}{l}\text { To what extent do you think that } \\
\text { children enjoy going to your child's } \\
\text { school? }\end{array}$ & Not at all & A little bit & Somewhat & Quite a bit & $\begin{array}{l}\text { A } \\
\text { tremendous } \\
\text { amount }\end{array}$ & & \\
\hline $\begin{array}{l}\text { Overall, how much respect do you think } \\
\text { the children at your child's school have } \\
\text { for the staff? }\end{array}$ & $\begin{array}{l}\text { Almost no } \\
\text { respect }\end{array}$ & $\begin{array}{l}\text { A little bit } \\
\text { of respect }\end{array}$ & $\begin{array}{l}\text { Some } \\
\text { respect }\end{array}$ & $\begin{array}{l}\text { Quite a bit } \\
\text { of respect }\end{array}$ & $\begin{array}{c}\text { A } \\
\text { tremendous } \\
\text { amount of } \\
\text { respect }\end{array}$ & & \\
\hline $\begin{array}{l}\text { Overall, how much respect do you think } \\
\text { the teachers at your child's school have } \\
\text { for the children? }\end{array}$ & $\begin{array}{l}\text { Almost no } \\
\text { respect }\end{array}$ & $\begin{array}{l}\text { A little bit } \\
\text { of respect }\end{array}$ & $\begin{array}{l}\text { Some } \\
\text { respect }\end{array}$ & $\begin{array}{l}\text { Quite a bit } \\
\text { of respect }\end{array}$ & $\begin{array}{c}\text { A } \\
\text { tremendous } \\
\text { amount of } \\
\text { respect }\end{array}$ & & \\
\hline $\begin{array}{l}\text { How much does the school value the } \\
\text { diversity of children's backgrounds? }\end{array}$ & Not at all & A little bit & Some & Quite a bit & $\begin{array}{l}\text { A } \\
\text { tremendous } \\
\text { amount }\end{array}$ & & \\
\hline \multicolumn{8}{|l|}{ Academic Climate } \\
\hline $\begin{array}{l}\text { How well do administrators at your } \\
\text { child's school create a school } \\
\text { environment that helps children learn? }\end{array}$ & $\begin{array}{l}\text { Not well } \\
\text { at all }\end{array}$ & $\begin{array}{l}\text { Mildly } \\
\text { well }\end{array}$ & $\begin{array}{l}\text { Fairly } \\
\text { well }\end{array}$ & Quite well & $\begin{array}{l}\text { Extremely } \\
\text { well }\end{array}$ & & \\
\hline $\begin{array}{l}\text { How motivating are the classroom } \\
\text { lessons at your child's school? }\end{array}$ & $\begin{array}{l}\text { Not at all } \\
\text { motivating }\end{array}$ & $\begin{array}{l}\text { Slightly } \\
\text { motivating }\end{array}$ & $\begin{array}{l}\text { Somewhat } \\
\text { motivating }\end{array}$ & $\begin{array}{l}\text { Quite } \\
\text { motivating }\end{array}$ & $\begin{array}{l}\text { Extremely } \\
\text { motivating }\end{array}$ & & \\
\hline $\begin{array}{l}\text { How fair or unfair is the school's } \\
\text { system of evaluating children? }\end{array}$ & $\begin{array}{l}\text { Very } \\
\text { unfair }\end{array}$ & $\begin{array}{l}\text { Somewhat } \\
\text { unfair }\end{array}$ & $\begin{array}{l}\text { Slightly } \\
\text { unfair }\end{array}$ & $\begin{array}{l}\text { Neither } \\
\text { fair nor } \\
\text { unfair }\end{array}$ & Slightly fair & $\begin{array}{l}\text { Somewhat } \\
\text { fair }\end{array}$ & Very fair \\
\hline
\end{tabular}




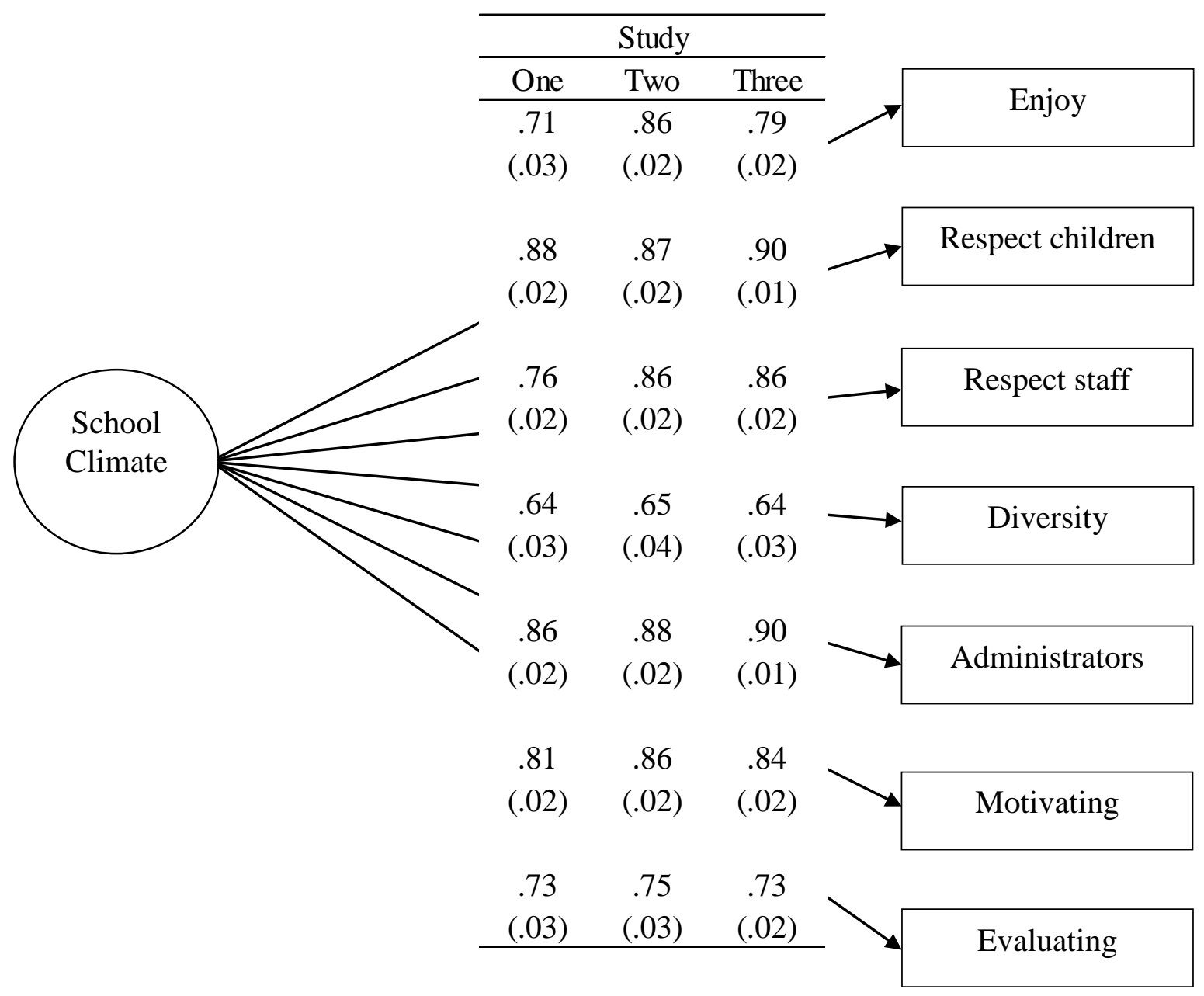

Figure 1. Standardized factor loadings and standard errors for the seven-item single-factor climate model with the samples from Studies One, Two and Three. 